\title{
A mechanistic understanding of repellent function against mammalian herbivores
}

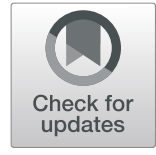

Rebecca S. Stutz ${ }^{1 *}$, Louisan Verschuur ${ }^{1,2}$, Olof Leimar ${ }^{1}$ and Ulrika A. Bergvall ${ }^{1,2}$

\begin{abstract}
Background: Browsing repellents are widely used to deter large herbivores from consuming plants of ecological, economic and aesthetic importance. Understanding how these repellents function on a behavioural mechanistic level is critical to predicting effectiveness. Here, we illustrate how these mechanisms can be tested, by exposing a model mammalian herbivore, the fallow deer, to different concentrations of a commercial chemical repellent (HaTe2) in two-choice feeding trials.

Results: The repellent acted as a defensive chemical for the food by both reducing visitation and the amount consumed. Deer favoured the less defended feeders before ingesting any food, suggesting that the repellent altered olfactory and/or visual cues. Deer also consumed less of the more defended food when choosing between low and high repellent feeders than no and low repellent feeders, indicating that the repellent modified flavour and/or sensation. Repellent effectiveness declined with increased exposure, suggesting that consumption had no negative post-ingestive effects, and thus, deterrence was not caused by a conditioned aversion or irritation. Instead, this pattern suggests that deer learned, through repeated sampling of repellent-treated food, that there was no adverse physiological effect of ingesting it.

Conclusions: These results imply that HaTe2 repellent will not be effective over prolonged periods or in the absence of alternative untreated food. Understanding the mechanisms driving repellent function using two-choice trials could help practitioners decide whether a particular repellent is likely to be effective against mammalian herbivory in their management scenario.
\end{abstract}

Keywords: Browse, Foraging decisions, Forestry, Ungulate, Wildlife damage

\section{Background}

Plants and herbivores interact in a complex and reciprocal manner: plants influence the health and distribution of herbivores, while herbivory modifies the composition and structure of plant communities (Augustine and McNaughton 1998). These interactions can have farreaching consequences for other plants and animals by influencing the availability of resources (Nuttle et al. 2011; Pedersen et al. 2007; Stephan et al. 2017), the success of revegetation efforts (Austin et al. 1994; Stutz et al. 2015) and productivity in agriculture and forestry (Putman and Moore 1998). One method for reducing damage by abundant mammalian herbivores is the application of chemical repellents to deter herbivores from

\footnotetext{
* Correspondence: rebecca.stutz@zoologi.su.se

${ }^{1}$ Department of Zoology, Stockholm University, SE-106 91 Stockholm,

Sweden

Full list of author information is available at the end of the article
}

high-value plants such as those used in cropping, timber production, restoration and gardening. While several commercial wildlife repellents are available, and some products have been tested for effectiveness (e.g. Conover 1984; El Hani and Conover 1998; Nolte 1998; Novellie and Bigalke 1981), we have an incomplete understanding of the behavioural mechanisms that underlie repellent function (or malfunction) in deterring mammalian herbivores from consuming plants.

Repellents may deter herbivores via one or more mechanisms that reduce the appeal of plants and thus influence foraging decisions. Kimball et al. (2009) defined four 'modes of action' for mammalian herbivore repellents: neophobia, irritation, flavour modification and conditioned taste aversion. We propose an extension of this framework that disentangles the sensory cues altered by repellents from the behavioural and physiological mechanisms that drive deterrence (Fig. 1). 


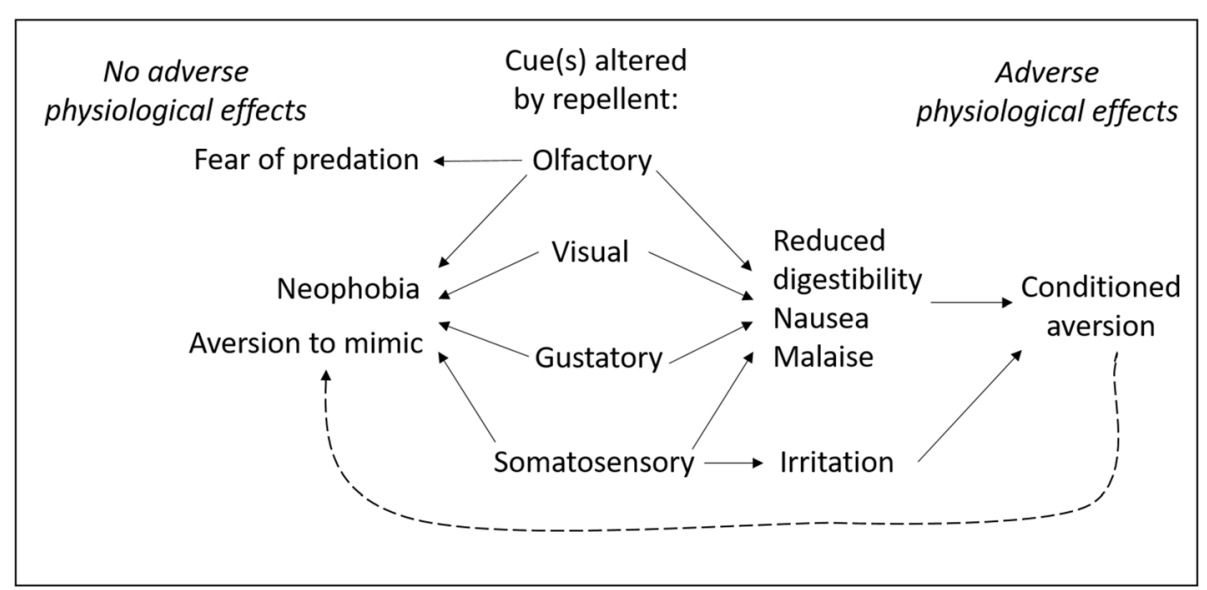

Fig. 1 Repellents alter the sensory cues of food and may deter herbivores via mechanisms both with and without realized physiological consequences of ingestion. The dotted line indicates the relationship between conditioned aversion and aversion to a mimic (a repellent mimicking cues associated with adverse physiological effects but without any adverse effects itself)

Repellents often change the smell and appearance of food, and these cues are apparent before the food is tasted. Once the animal takes a bite, it experiences the flavour and feeling of the food in its mouth and this can also be modified by a chemical repellent. The association, or not, of these cues with previous experiences and adverse physiological effects determines how effectively the repellent deters herbivores from consuming treated food (Kimball and Taylor 2010).

Repellents that do not cause any adverse physiological effects rely on cues that induce innate or learned avoidance behaviours. For example, those based on neophobia take advantage of the fear of novel stimuli (Cassini 1994; Villalba and Provenza 2000). However, if a repellent only consists of a novel taste, texture, smell or colour, without any negative post-ingestive consequences, its effectiveness generally decreases with exposure time as animals learn to incorporate it in their diet (Nolte 1999). This is probably a consequence of post-ingestive learning (Arnould and Signoret 1993; Provenza 1995), in combination with the continuous sampling behaviour of mammalian herbivores (Provenza et al. 1998), with the speed of learning depending on an animal's nutritional status and the availability of alternative food (Provenza 1995).

Another category of repellents is based on herbivores' innate fear of predation, often induced using odour cues from predator urine and faeces, or sulphurous compounds associated with predation (Bean et al. 1997; Pfister et al. 1990; Sullivan et al. 1985; Woolhouse and Morgan 1995). Much like the repellents based on novelty, those based on fear of predation are infrequently reinforced by experience; unless predation pressure is high, there are relatively few opportunities to associate the cue with the presence of a predator or a predation event in the herd. Their effects can thus be short-lived, particularly in the absence of alternative food (Murray et al. 2006).

In contrast, repellents that cause pain or discomfort on contact with the mouth, nose or eyes generally have immediate deterrent effects (Beauchamp 1997; Mason 1998), possibly because these irritants mimic the compounds released during tissue damage (Clark 1997). There is some evidence that repellents containing compounds that activate the trigeminal system, such as capsaicin, deter mammalian herbivores from consumption when applied at high concentrations, but hunger appears to reduce the deterrent effect (Andelt et al. 1992; Andelt et al. 1994).

Animals experiencing sensory cues associated with malaise or gastrointestinal distress, such as those indicating the presence of tannins or lithium chloride, can develop conditioned aversions (Burritt and Provenza 1989; Provenza 1996; Provenza et al. 1990). The effects of these repellents are typically long-lasting as repeated sampling by herbivores reinforces the negative association between flavour and consequence. Conditioned aversions may even extend to mimicking cues associated with experiences of negative post-ingestive effects (Massei et al. 2007).

A single repellent may employ one or a combination of sensory cues and behavioural mechanisms to deter herbivores from consuming treated plants. A large number of repellents exist and have been tested for efficacy in the field, but we currently do not have a mechanistic understanding of how these repellents operate to deter herbivores. This is important for predicting repellent effectiveness under variable field conditions and the factors that could lead to failure. Our objective was to develop a simple behavioural experiment for determining 
the mechanisms of deterrence and modes of action employed by commercial repellents.

We used two-choice feeding trials to quantify the behavioural responses of a model mammalian herbivore, the fallow deer (Dama dama), to food varying in repellent concentration. We chose the commercial repellent HaTe2 (Fluegel $\mathrm{GmbH}$, Germany), a black viscous liquid comprised of ethanol, balsam resin and black pigment. Given that the repellent altered the appearance, smell and possibly taste and texture of food, we hypothesised that the mechanisms behind its deterrent function would be twofold: first by reducing the frequency with which animals chose the food and second by reducing the amount of food they ingested as a function of repellent concentration. For each sensory and behavioural mechanism that could be involved in deterring food consumption, we specified the foraging behaviour that we would expect from the deer (Table 1). Some modes of action are more robust than others; thus, understanding how a chemical repellent functions at the behavioural level is critical for predicting its performance as a herbivore deterrent.

\section{Methods}

\section{Experimental design}

We used seven adult female fallow deer that were born in 2000 and had been hand-reared, making them amenable to conducting individual paired-choice feeding trials. They were held in a 4-ha enclosure at Tovetorp Research Station (Stockholm University, south-central Sweden). The enclosure comprised a sloping meadow with low-lying shallow waterbodies and a variety of trees including spruce Picea abies, Scots pine, silver birch Betula pendula, downy birch Betula pubescens, Norway maple Acer platanoides, rowan Sorbus aucuparia, aspen Populus tremula, alder Alnus glutinosa, hazel Corylus avellana, oak Quercus robur and small-leaved lime Tilia cordata. The deer had ad libitum access to water, minerals and a salt stone throughout the study period (26th of January to 26th of February, 2016). The food consumed during trials constituted more than their normal daily intake, so no additional food was provided on trial days.

Fallow deer were offered a choice between food treated with different concentrations of $\mathrm{HaTe} 2$ repellent. We used Renfor pellets (manufacturer: Lantmännen, Nyköping), a product specifically designed for cervids that contains dried beet pulp and molasses, oats, wheat, malt sprouts, distiller's grains, corn, rapeseed and sodium chloride (crude protein $=100 \mathrm{~g} \mathrm{~kg}^{-1}$, energy $=11.2 \mathrm{MJ}$ $\mathrm{kg}^{-1}$ ). We used a hand-pressurized spray bottle to apply the repellent to pellets at three wet-weight concentrations: high $\left(70 \mathrm{~g} \mathrm{~kg}^{-1}\right)$, low $\left(7 \mathrm{~g} \mathrm{~kg}^{-1}\right)$ and control (none applied). Testing occurred with one individual at a time led to the entrance of a triangular pen in a corner of their enclosure. Animals were presented with two clay bowls (feeders, $23 \mathrm{~cm}$ in diameter) at $20 \mathrm{~cm}$ apart, containing $200 \mathrm{~g}$ of food each in one of two repellent combinations: no and low, or low and high. We expected that adding repellent would alter the food quality perceived by deer by artificially increasing defence against herbivores. The level of defence was expected to be lowest in feeders with no repellent and highest in feeders with high repellent concentration; the defence of low repellent feeders should then be relative to the alternative feeder offered. Both positive and negative simultaneous contrasts have been previously demonstrated in fallow deer (Bergvall and Balogh 2009) and are potentially important when applying repellents in forests because this may create contrasts between treated and untreated plants, with the untreated plants themselves having variable levels of natural plant defences.

We randomly allocated treatments and the position of the feeders (left/right). The trial endpoint was when the animal had eaten all the food in one of the feeders. The remaining feeder was then removed and food weighed. During each trial, we also recorded at which feeder the animal initiated feeding and the number of times they switched feeders. The former indicates whether or not deer used visual and/or olfactory cues at a distance to

Table 1 The expected foraging responses of fallow deer for each potential mechanism of repellent function. Deer were exposed to two-choice food trials with no and low or low and high concentrations of repellent (more repellent = more defended)

\begin{tabular}{ll}
\hline Mechanisms & Expected foraging response \\
\hline Sensory cues altered & \\
Olfactory/visual & -Fewer trials involve consumption from more defended feeder in pair \\
& -More likely to initiate consumption at less defended feeder in pair \\
Gustatory/somatosensory & - Shift between feeders more often when consumption initiated at more defended feeder in pair \\
& - Consume more from less defended feeder in pair \\
& -More selective for less defended feeder in more defended (low-high) pair
\end{tabular}


select feeders, while the latter suggests the level of indecision or satisfaction with their current choice. We performed one two-choice trial per day with each of the seven fallow deer for 10 days, except one individual (\#7) which only participated in seven trials (thus $N=67$ ). Deer were involved in trials for a maximum of four consecutive days, followed by a break of at least 5 days before trials recommenced.

\section{Statistical analyses}

We tested whether initial feeder choice was a function of relative repellent concentration within two-choice pairs (less or more), the type of two-choice pair (no-low or low-high) and their interaction. We fitted a generalized linear model (GLM) specifying a binomial response variable (initial feeder $=1$, otherwise $=0$, for each of the two feeders in a trial) with logit link function. We could not include trial day and animal identity as random effects because in this logistic model, each level of these factors necessarily consisted of equal numbers of 0's and 1's (i.e. where one bowl was chosen first, the other was not). A model that included these random effects as interaction terms with relative defence failed to converge.

To test if the first feeder chosen in a trial had any effect on the number of times each deer switched between feeders, we fitted a generalized linear mixed effects model (GLMM) specifying a Poisson response distribution with $\log$ link function. We included relative defence and pair type as fixed effects, as in the previous model. We also included trial day and animal identity as random effects, accounting for potential effects of uncontrollable conditions on a trial day (e.g. temperature, cloud cover, environmental noise) and of consistent foraging behaviours by individual deer (Bergvall 2009).

We used a linear mixed effects model (LMM) to test how relative defence and type of two-choice pair affected food consumption, including trial day and animal identity as random effects. Here, we also included trial day as a continuous fixed effect to determine whether the amount consumed by deer in a trial changed over consecutive trials.

Repellents often become less effective at deterring herbivores with increasing exposure. We therefore tested how selective deer were across the five replicates of the two types of two-choice pair. We divided the amount consumed from the less defended feeder in each pair (no in no-low and low in low-high) by the total consumption across both feeders in each trial. We then fitted a LMM with the treatment replicate number as a continuous fixed effect and animal identity as a random effect.

We performed all statistical analyses using the 'Ime4' package (Bates et al. 2015) in $\mathrm{R}$ version 3.2.2 ( $\mathrm{R}$ Core Team 2016). We report the significance of the type II
Wald chi-square tests derived using the 'car' package (Fox and Weisberg 2011). Quantile-quantile plots were checked for approximation of normality.

\section{Results}

All the deer consumed food from at least one feeder in each trial. In no-low pairs ( $N=33$ trials), deer consumed food from both feeders in $70 \%$ of trials, exclusively from no-repellent feeders in $27 \%$ of trials and exclusively from low-repellent feeders in 3\% of trials. In low-high pairs ( $N=34$ trials), deer consumed from both feeders in 59\% of trials, exclusively low-repellent feeders in $35 \%$ of trials and exclusively high-repellent feeders in $6 \%$ of trials.

\section{First feeder selected}

When presented with a choice between two feeders with no and low, or low and high concentrations of $\mathrm{HaTe} 2$ repellent, fallow deer were more likely to initiate trials at the less defended feeder in the two-choice pair (relative defence, $X^{2}{ }_{1}=5.07, P=0.024$; Fig. 2). There was no interaction between relative defence and pair type $\left(\chi^{2}{ }_{1}=0.24\right.$, $P=0.621$ ); pair type itself was not of interest as probabilities of selection within pairs were equal to $1\left(\chi^{2}{ }_{1}=0\right.$, $P=1)$.

\section{Number of feeder shifts}

Deer changed feeders more often when they started the trial at the more defended feeder (relative defence of first feeder, $X^{2}{ }_{1}=7.84, P=0.005$; Fig. 3 ). The pair type and its interaction with relative defence of first feeder were not significant (pair, $X^{2}{ }_{1}=0.10, P=0.752$; interaction, $X^{2}{ }_{1}=$ $0.91, P=0.339)$.

\section{Amount consumed}

There was a significant interactive effect of relative defence and pair type on the amount consumed by deer: consumption from the more defended feeder was greater

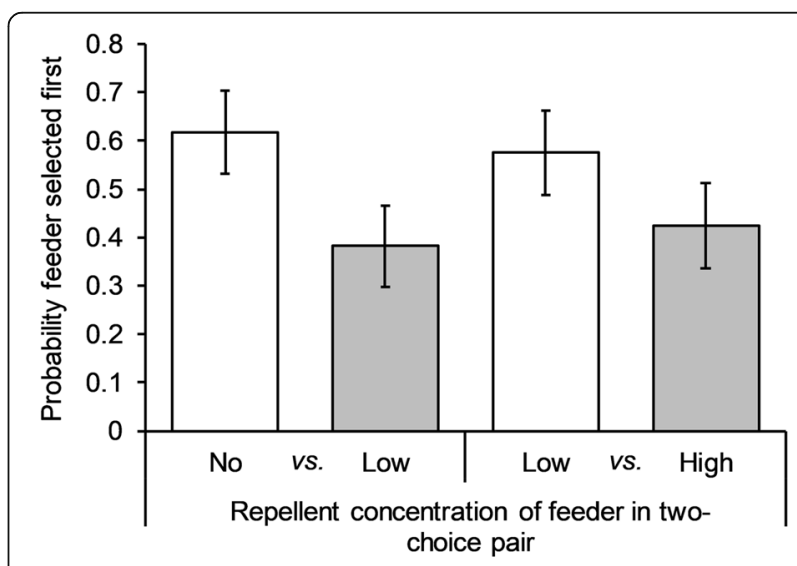

Fig. 2 The probability of fallow deer initiating consumption at each feeder within two-choice pairs $( \pm \mathrm{SE})$ 


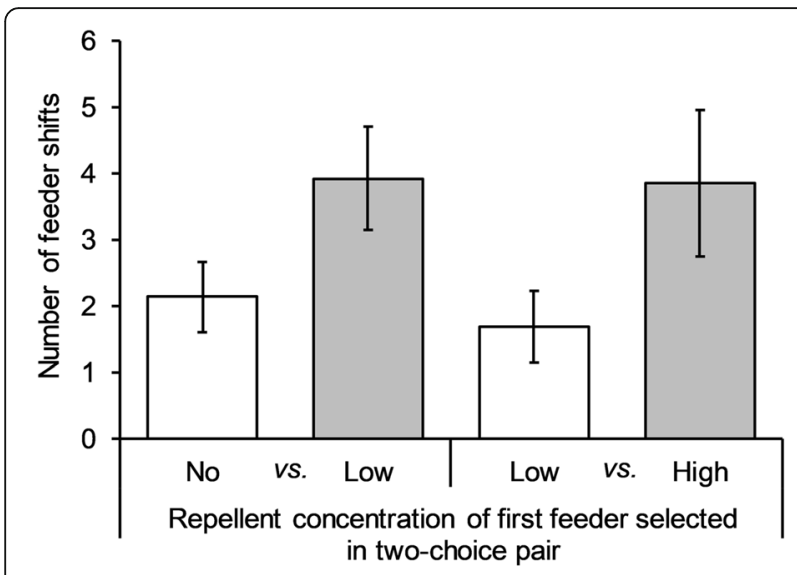

Fig. 3 The number of times fallow deer shifted between feeders as a function of initial feeder selected $( \pm$ SE)

in no-low pairs than in low-high pairs, while consumption from the less defended feeder was greater in lowhigh pairs than in no-low pairs (interaction, $X^{2}{ }_{1}=7.30$, $P=0.007$; Fig. 4). Overall, deer ate more from the less defended feeders in each pair (relative defence, $X^{2}{ }_{1}=$ 44.42, $P<0.0001$ ). Pair type and the number of trials that deer completed had no significant effect on the total amount of food consumed by deer in a trial (pair, $\chi^{2}{ }_{1}=$ 2.66, $P=0.103$; trial day, $X^{2}{ }_{1}=1.44, P=0.230$ ).

\section{Selectivity as a function of exposure}

The proportion of consumption comprising lower repellent food was greater in low-high than no-low repellent pairs (pair, $X^{2}{ }_{1}=5.71, P=0.017$; Fig. 5). Selectivity for the lower repellent food decreased with the number of trials each deer was exposed to in both types of two-choice pairs (replicate, $\chi^{2}{ }_{1}=5.79, P=0.016$ ). The rate at which selectivity decreased over time was not significantly different between pair types (interaction, $\chi^{2}{ }_{1}=$ $0.70, P=0.402$ ).

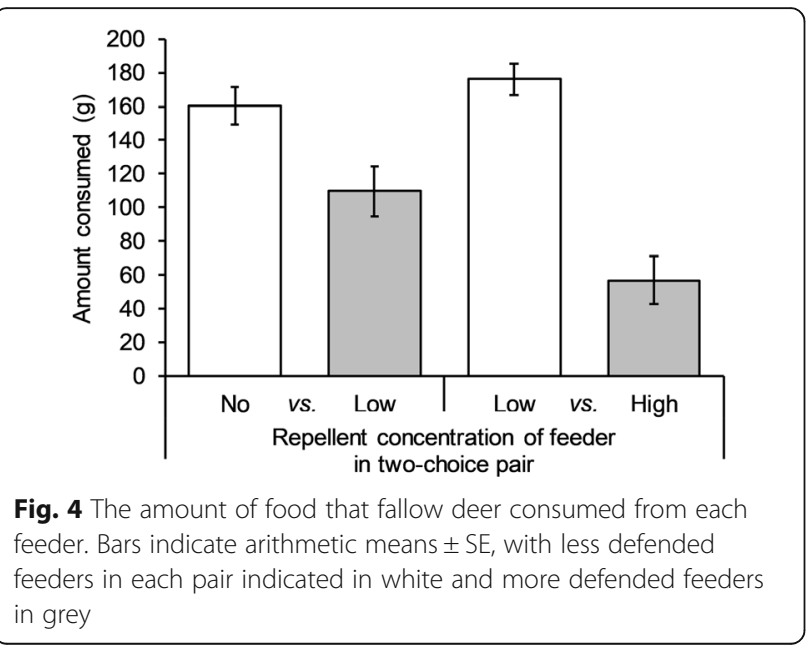

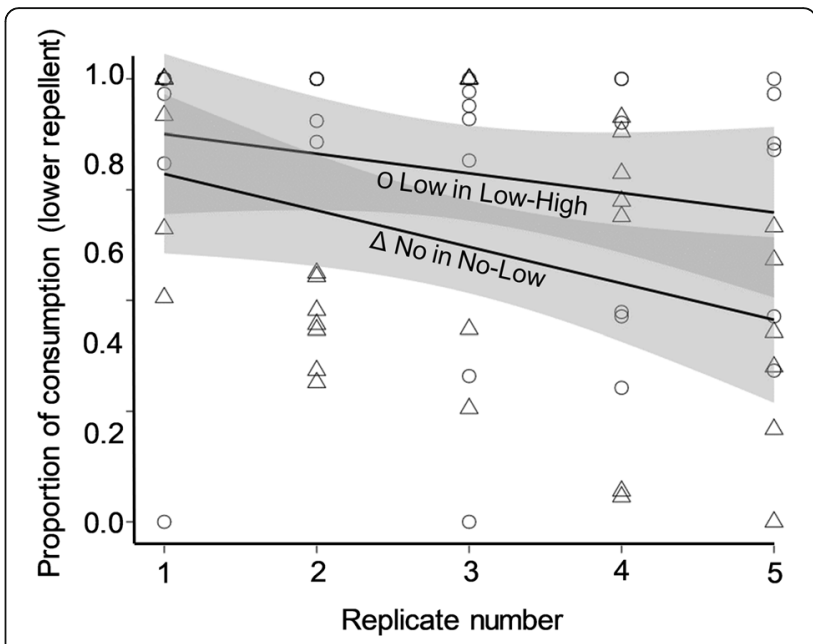

Fig. 5 The consumption per treatment replicate of the lower repellent food (no in no-low and low in low-high) as a proportion of total consumption. Shading indicates $95 \%$ confidence limits

\section{Discussion}

Browsing by large herbivores can cause significant damage to plants that are important in forestry, agriculture and restoration, yet chemical repellents to deter browsing are not well understood from a behavioural perspective. Using simple two-choice trials with captive fallow deer, we demonstrated the mechanisms of deterrence operating behind a commercial herbivore repellent, HaTe2. We found evidence of both reduced visitation to more defended (higher repellent) feeders and reduced consumption while there. The patterns of consumption from differentially defended pairs of feeders supported a mechanism that included pre-ingestive cues (olfactory and/or visual) and lacked adverse physiological consequences post-ingestion. The two-choice tests therefore provided critical information about the contexts in which the repellent is likely to be effective.

In the majority of trials, the deer consumed food from both feeders but, consistent with our predictions, they chose the higher repellent (more defended) food less often and very rarely consumed the higher repellent food exclusively. Deer were more likely to initiate consumption at the lower repellent (less defended) feeder, showing some ability to differentiate between more and less defended feeders prior to tasting. They may have used visual or olfactory cues coupled to food quality to select the first feeder in a trial. Fallow deer are known to be able to use colour to discriminate between visual stimuli (Birgersson et al. 2001). In addition, there is mounting evidence that colour and odour are important cues used to detect and assess palatable food plants by mammalian herbivores that consume green vegetation, not just for those consuming fruits and fungi (Schmitt et al. 2018; Stutz et al. 2016; Stutz et al. 2017). 
When deer did initiate feeding at the more defended feeder, they were more indecisive, switching more often between feeders. This behaviour is consistent with that observed when applying compounds extracted from birch bark (Betula spp.) to food; in a two-choice experiment consisting of test and control feeders, fallow deer switched feeders more often when test feeders contained higher concentrations of the extract (Bergvall et al. 2013). We suggest that repellent residue on the tongue may have made subsequent comparisons with the other feeder in the pair more difficult.

The absolute amount that deer consumed during trials did not differ significantly between no-low and low-high pairs. However, the repellent had the effect of suppressing intake of the more defended food, with deer eating a greater amount from the less defended feeder in both treatment pairs (no in no-low and low in low-high pairs) . This is consistent with the idea that repellents are more effective when there are alternative (better) food options available (Kimball et al. 2002; Provenza 1995). Consumption of the more defended food was higher in no-low than low-high pairs, suggesting that the repellent modified flavour (odour, taste and texture) and that flavour intensity played a role in food selection (Villalba and Provenza 2000).

The effectiveness of the repellent declined over time in both two-choice pairs, with deer becoming less selective for the less defended feeder in each pair as trials progressed. This suggests that consumption of $\mathrm{HaTe} 2$ repellent in food did not have significant post-ingestive consequences for fallow deer (Kimball et al. 2009). Alternatively, the effects of toxins or digestibility-reducing compounds in the repellent may have been partly negated by the high nutritional value of the food compared to natural forage. Detoxification, deactivation or elimination of toxic and anti-nutritional compounds require nutrients and water and thus can be achieved more quickly when food is nutrient-rich (Illius and Jessop 1995; Provenza et al. 2003). The deer may therefore have learned over successive trials that the cost of ingesting the more defended food was not very high; as a result, they may have reduced their effort in selecting between feeders and instead attempted to maximize total intake or rate of intake. This could have implications for the use of repellents near supplementary feeding stations; animals feeding from stations would have enhanced detoxification abilities, decreasing the effectiveness of repellents applied to surrounding trees (Provenza et al. 2003; Timmons et al. 2010).

\section{Conclusions}

Our study provides evidence that $\mathrm{HaTe} 2$ repellent altered both pre- and post-ingestive cues perceived by deer and suggests that these cues were not coupled with significant physiological consequences. This has implications for the effectiveness of the repellent both temporally and spatially: herbivore deterrence is likely to decrease with prolonged exposure to the repellent and with lower availability of alternative feeding options nearby. As a result, the repellent may not be appropriate in some contexts or require application patterns to be modified by, for example, using rotations of different repellents to maintain novelty, leaving some plants untreated as sacrificial feed or providing supplementary feed.

Decisions about applying herbivore-repelling chemicals to plants over large areas, such as in forestry and agricultural operations, should be informed by the behavioural mechanisms responsible for the deterrent effects. We demonstrated how simple two-choice feeding trials can be used to understand herbivore responses to repellents. The characteristics of the herbivores and plants in an area will influence these responses and thus the effectiveness of a repellent. For example, the effectiveness of a repellent will likely be lower where the nutritive value of the plant is high relative to other available food, there is little alternative food or the herbivore density is high. We therefore suggest that this type of experimentation could be used to select effective mechanisms of plant protection for particular management scenarios and reduce the risk of repellent failure in large-scale field applications.

\section{Abbreviations \\ GLMM: Generalized linear mixed effects model; LMM: Linear mixed effects model}

\section{Acknowledgements}

We thank Sven Jakobsson, Thomas Giegold, Nils Andbjer and Susanna Gustavsson for facilitating the fieldwork at Tovetorp Research Station and Benjamin Croak for building experimental pens.

\section{Authors' contributions}

UAB conceived and designed the experiment. LV and RSS performed the experiment. RSS analysed the data and wrote the manuscript; all other authors provided editorial advice. All authors approved the final version of the manuscript.

\section{Funding}

The Swedish Research Council FORMAS awarded to UAB. The funding body had no role in any part of the study.

\section{Availability of data and materials}

The datasets generated and/or analysed during the current study will be available in the Mendeley Data repository (https://doi.org/10.17632/ ycdr6yr3dx.1).

\section{Ethics approval and consent to participate}

Research procedures were approved by the Swedish National Board for Laboratory Animals (Dnr 14-14).

Consent for publication

Not applicable.

Competing interests

The authors declare that they have no competing interests. 


\section{Author details}

1Department of Zoology, Stockholm University, SE-106 91 Stockholm, Sweden. ${ }^{2}$ Grimsö Wildlife Research Station, Department of Ecology, Swedish University of Agricultural Sciences, SE-730 91 Riddarhyttan, Sweden.

\section{Received: 23 November 2018 Accepted: 29 May 2019}

\section{Published online: 03 July 2019}

\section{References}

Andelt WF, Baker DL, Burnham KP (1992) Relative preference of captive cow elk for repellent-treated diets. J Wildl Manag 56:164-173

Andelt WF, Burnham KP, Baker DL (1994) Effectiveness of capsaicin and bitrex repellents for deterring browsing by captive mule deer. J Wildl Manag 58 330-334. https://doi.org/10.2307/3809398

Arnould C, Signoret JP (1993) Sheep food repellents: efficacy of various products, habituation, and social facilitation. J Chem Ecol 19:225-236. https://doi.org/ 10.1007/bf00993691

Augustine DJ, McNaughton SJ (1998) Ungulate effects on the functional species composition of plant communities: herbivore selectivity and plant tolerance. Jildl Manag 62:1165-1183. https://doi.org/10.2307/3801981

Austin DD, Urness PJ, Durham SL (1994) Impacts of mule deer and horse grazing on transplanted shrubs for revegetation. J Range Manag 47:8-11. https://doi. org/10.2307/4002832

Bates D, Maechler M, Bolker B, Walker S (2015) Fitting linear mixed-effects models using Ime4. J Stat Softw 67:1-48. https://doi.org/10.18637/jss.v067.i01

Bean N, Korff W, Mason J (1997) Repellency of plant, natural products and predator odors to woodchucks. In: Mason J (ed) Repellents in Wildlife Management. Colorado State University, Denver

Beauchamp GK (1997) Chemical signals and repellency: problems and prognosis. In: Mason JR (ed) repellents in wildlife management. Ft.Collins: National Wildlife Research Center, pp 1-10

Bergvall UA (2009) Development of feeding selectivity and consistency in food choice over 5 years in fallow deer. Behav Proc 80:140-146. https://doi.org/10. 1016/j.beproc.2008.11.004

Bergvall UA, Balogh ACV (2009) Consummatory simultaneous positive and negative contrast in fallow deer: implications for selectivity. Mamm Biol 74: 236-239. https://doi.org/10.1016/j.mambio.2008.05.004

Bergvall UA, Co M, Bergström R, Sjöberg PJR, Waldebäck M, Turner C (2013) Antibrowsing effects of birch bark extract on fallow deer. Eur J For Res 132:717725. https://doi.org/10.1007/s10342-013-0709-y

Birgersson B, Alm U, Forkman B (2001) Colour vision in fallow deer: a behavioural study. Anim Behav 61:367-371. https://doi.org/10.1006/anbe.2000.1603

Burritt EA, Provenza FD (1989) Food aversion learning: conditioning lambs to avoid a palatable shrub (Cercocarpus montanus). J Anim Sci 67:650-653

Cassini MH (1994) Behavioral mechanisms of selection of diet components and their ecological implications in herbivorous mammals. J Mammal 75:733-740. https://doi.org/10.2307/1382523

Clark L (1997) Physiological, ecological, and evolutionary bases for the avoidance of chemical irritants by birds. In: Nolan V, Ketterson ED, Thompson CF (eds) Curr. Ornithol. Springer US, Boston, MA, pp 1-37

Conover MR (1984) Effectiveness of repellents in reducing deer damage in nurseries. Wildl Soc Bull 12:399-404

El Hani A, Conover MR (1998) Comparative analysis of deer repellents. In: Mason $J R$ (ed) Repellents in wildlife management. Colorado state press Universtity, Ft. Collins, pp 147-155

Fox J, Weisberg S (2011) An R companion to applied regression second edition edn. Sage, Thousand Oaks CA

Illius AW, Jessop NS (1995) Modeling metabolic costs of allelochemical ingestion by foraging herbivores. J Chem Ecol 21:693-719. https://doi.org/10.1007/ bf02033456

Kimball BA, Provenza FD, Burritt EA (2002) Importance of alternative foods on the persistence of flavor aversions: implications for applied flavor avoidance learning. Appl Anim Behav Sci 76:249-258

Kimball BA, Taylor J, Perry KR, Capelli C (2009) Deer responses to repellent stimuli. J Chem Ecol 35:1461-1470. https://doi.org/10.1007/s10886-009-9721-6

Kimball BA, Taylor JD (2010) Mammalian herbivore repellents: tools for altering plant palatability. Outlooks on Pest Management 21:181-187. https://doi.org/ 10.1564/21aug09

Mason JR (1998) Mammal repellents: options and considerations for development. In: Baker RO, Crabb AC (eds) Proceedings of the 18th vertebrate Pest conference. University of California, Davis
Massei G, Cotterill JV, Coats JC, Bryning G, Cowan DP (2007) Can Batesian mimicry help plants to deter herbivores? Pest Manag. Sci 63:559-563. https://doi.org/10. 1002/ps.1360

Murray PJ, Burns AC, Davy JR (2006) Development of an animal repellent: selection, efficacy and presentation. Aust J Exp Agric 46:851-856. https://doi. org/10.1071/EA06004

Nolte DL (1998) Efficacy of selected repellents to deter deer browsing on conifer seedlings. Int Biodeterior Biodegrad 42:101-107. https://doi.org/10.1016/ S0964-8305(98)00008-0

Nolte DL (1999) Behavioral approaches for limiting depredation by wild ungulates. In: Launchbaugh KL, Sanders D, Mosely JC (eds) Grazing behavior of livestock and wildlife. University of Idaho, Moscow, pp 60-69

Novellie P, Bigalke RC (1981) An assessment of antelope browse damage in a pine plantation and an evaluation of some chemical repellents. South African Forestry Journal 119:8-13. https://doi.org/10.1080/00382167.1981.9630217

Nuttle T, Yerger EH, Stoleson SH, Ristau TE (2011) Legacy of top-down herbivore pressure ricochets back up multiple trophic levels in forest canopies over 30 years. Ecosphere 2:art4. https://doi.org/10.1890/es10-00108.1

Pedersen S, Nilsen EB, Andreassen HP (2007) Moose winter browsing affects the breeding success of great tits. Ecoscience 14:499-506. https://doi.org/10. 2980/1195-6860(2007)14[499:mwbatb]2.0.co;2

Pfister JA, Müller-Schwarze D, Balph DF (1990) Effects of predator fecal odors on feed selection by sheep and cattle. J Chem Ecol 16:573-583. https://doi.org/ 10.1007/bf01021787

Provenza FD (1995) Postingestive feedback as an elementary determinant of food preference and intake in ruminants. J Range Manag 48:2-17. https://doi. org/10.2307/4002498

Provenza FD (1996) Acquired aversions as the basis for varied diets of ruminants foraging on rangelands. J Anim Sci 74:2010-2020

Provenza FD, Burritt EA, Clausen TP, Bryant JP, Reichardt PB, Distel RA (1990) Conditioned flavor aversion: a mechanism for goats to avoid condensed tannins in blackbrush. Am Nat 136:810-828. https://doi.org/10.1086/285133

Provenza FD, Villalba JJ, Cheney CD, Werner SJ (1998) Self-organization of foraging behaviour: from simplicity to complexity without goals. Nutr Res Rev 11: 199-229

Provenza FD, Villalba JJ, Dziba LE, Atwood SB, Banner RE (2003) Linking herbivore experience, varied diets, and plant biochemical diversity. Small Ruminant Res 49 257-274. https://doi.org/10.1016/S0921-4488(03)00143-3

Putman RJ, Moore NP (1998) Impact of deer in lowland Britain on agriculture, forestry and conservation habitats. Mammal Rev 28:141-164. https://doi.org/ 10.1046/j.1365-2907.1998.00031.x

R Core Team (2016) R: a language and environment for statistical computing. R Foundation for Statistical Computing, Vienna, Austria

Schmitt MH, Shuttleworth A, Ward D, Shrader AM (2018) African elephants use plant odours to make foraging decisions across multiple spatial scales. Anim Behav 141:17-27. https://doi.org/10.1016/j.anbehav.2018.04.016

Stephan JG, Pourazari F, Tattersdill K, Kobayashi T, Nishizawa K, De Long JR (2017) Long-term deer exclosure alters soil properties, plant traits, understory plant community and insect herbivory, but not the functional relationships among them. Oecologia 184:685-699. https://doi.org/10.1007/s00442-017-3895-3

Stutz RS, Banks PB, Dexter N, McArthur C (2015) Associational refuge in practice: can existing vegetation facilitate woodland restoration? Oikos 124:571-580. https://doi.org/10.1111/oik.01782

Stutz RS, Banks PB, Proschogo N, McArthur C (2016) Follow your nose: leaf odour as an important foraging cue for mammalian herbivores. Oecologia 182:643651. https://doi.org/10.1007/s00442-016-3678-2

Stutz RS, Croak BM, Proschogo N, Banks PB, McArthur C (2017) Olfactory and visual plant cues as drivers of selective herbivory. Oikos 126:259-268. https:// doi.org/10.1111/oik.03422

Sullivan TP, Nordstrom LO, Sullivan DS (1985) Use of predator odors as repellents to reduce feeding damage by herbivores: II. Black-tailed deer (Odocoileus hemionus columbianus). J Chem Ecol 11:921-935. https://doi.org/10.1007/bf01012078

Timmons GR, Hewitt DG, Deyoung CA, Fulbright TE, Draeger DA (2010) Does supplemental feed increase selective foraging in a browsing ungulate? J Wild Manag 74:995-1002. https://doi.org/10.2193/2009-250

Villalba J, Provenza F (2000) Roles of flavor and reward intensities in acquisition and generalization of food preferences: do strong plant signals always deter herbivory? J Chem Ecol 26:1911-1922. https://doi.org/10.1023/A: 1005552925338

Woolhouse A, Morgan D (1995) An evaluation of repellents to suppress browsing by possums. J Chem Ecol 21:1571-1583. https://doi.org/10.1007/bf02035153 


\section{Publisher's Note}

Springer Nature remains neutral with regard to jurisdictional claims in published maps and institutional affiliations.

Submit your manuscript to a SpringerOpen ${ }^{\mathcal{O}}$ journal and benefit from:

- Convenient online submission

- Rigorous peer review

- Open access: articles freely available online

- High visibility within the field

- Retaining the copyright to your article

Submit your next manuscript at $\boldsymbol{\triangleright}$ springeropen.com 